\title{
Differentiating the impact of anatomic and non-anatomic liver resection on early recurrence in patients with Hepatocellular Carcinoma
}

\author{
Karim M Eltawil1,2, Mark Kidd'1, Francesco Giovinazzo1, Ahmed H Helmy² and Ronald R Salem*1
}

\begin{abstract}
Background: For Hepatocellular Carcinoma (HCC) treated with hepatectomy, the extent of the resection margin remains controversial and data available on its effect on early tumor recurrence are very few and contradictory. The purpose of this study was to compare the impact of the type of resection (anatomic versus non-anatomic) on early intra-hepatic HCC recurrence in patients with solitary HCC and preserved liver function.

Methods: Among 53 patients with similar clinico-pathologic data who underwent curative liver resection for HCC between 2000 and 2006, 28 patients underwent anatomic resection of at least one liver segment and 25 patients underwent limited resection with a margin of at least $1 \mathrm{~cm}$.

Results: After a close follow-up period of 24 months, no difference was detected in recurrence rates between the anatomic (35.7\%) and the non-anatomic (40\%) groups in either univariate $(p=0.74)$ and multivariate $(p=0.65)$ analysis. Factors contributing to early recurrence were tumor size $(p=0.012)$ and tumor stage including vascular invasion $(p=$ 0.009).

Conclusion: The choice of the type of resection for HCC should be based on the maintenance of adequate hepatic reserve. The type of resection (anatomic vs non-anatomic) was found not to be a risk factor for early tumor recurrence.
\end{abstract}

\section{Background}

HCC is considered the fifth most frequent cancer in the world and the third most common cause of cancer related mortality [1]. Although more common in Asia and Africa, the incidence of HCC is increasing in the Western world [2]. According to the Surveillance and Epidemiology End Results (SEER) registries, the average age adjusted incidence of $\mathrm{HCC}$ in the United States increased from 1.3 per 100,000 in $1978-1980$ to 6.6 per 100,000 based on cases diagnosed in 2002-2006 from 17 SEER geographic areas [3].

Resection for HCC is a widely accepted safe treatment with a very low operative mortality as a result of advances in surgical techniques and peri-operative management [4]. However, identifying an optimum extent of resection is often difficult due to underlying liver disease such as chronic hepatitis or cirrhosis in most patients [5]. Based

* Correspondence: ronald.salem@yale.edu

1 Department of Surgery, Yale University School of Medicine, New Haven, Connecticut, USA

Full list of author information is available at the end of the article on the fact that cirrhotic liver has limited capacity to regenerate [6], many surgeons perform limited resection for $\mathrm{HCC}$, focusing on the preservation of $1 \mathrm{~cm}$ or greater tumor-free margin to reduce postoperative liver failure in patients with cirrhosis [7]. Anatomic liver resection is theoretically superior to non-anatomic from the oncologic and anatomic aspects [8], however, this technique is considered technically more demanding and often requires a wider extent of parenchymal sacrifice $[4,9]$. Additionally, several clinical studies have failed to document any improvement in survival [10-12].

The rate of development of postoperative recurrence after hepatic resection remains high [13]. Early recurrence within 2 years of hepatic resection for $\mathrm{HCC}$ is likely to be associated with aggressive tumor biology such as high tumor grade, satellite lesions and microvascular invasion [14].

This retrospective study compares the impact of anatomic and non-anatomic resections on early recurrence in HCC patients over a 2 year period. Other pre and peri- 
operative factors were also evaluated between the two groups.

\section{Methods}

This study was approved by the Human Investigation Committee (HIC) of Yale University as well as the Ethical Committee of Theodor Bilharz Research Institute (TBRI).

\section{Patients}

Between 2000 and 2006, 53 patients who had a preoperative diagnosis of a single HCC and who underwent hepatectomy at Yale-New Haven Hospital and TBRI-General Hospital were included in the study. The pre-operative investigations included blood chemistry, hepatitis B \& C markers, alpha-fetoprotein (AFP), abdominal ultrasonography (US), computed tomography (CT), chest radiography with or without liver biopsy based on the diagnostic criteria of the American Association for the Study of Liver Diseases (AASLD) [15]. All selected patients had compensated cirrhosis with Child-Pugh class A/early B or were non-cirrhotics.

\section{Patient characteristics}

The following clinical variables were compared in the two groups: age, sex, viral markers (Hepatitis B [HB] virus surface antigen, anti-HB core antibody, anti-HB surface antibody, hepatitis $C$ virus antibody), presence or absence of cirrhosis, serum albumin, serum total bilirubin, ChildPugh classification and serum AFP (Table 1).

\section{Hepatectomy procedures}

The patients were divided into two groups. Anatomic resection $(\mathrm{n}=28)$ was defined as the complete removal of at least 1 Couinaud's segment containing the tumor together with the related portal vein and the corresponding hepatic territory. The appropriate segment margins were identified by intra-operative US after discoloration of the parenchyma after ligation of the corresponding arterial and portal venous branches or both. Non-anatomic resection $(\mathrm{n}=25)$ was defined as the resection of the tumor with a margin of at least $1 \mathrm{~cm}$ without regard to segmental, sectional or lobar anatomy. There was no evidence of extra-hepatic metastasis. All patients underwent intraoperative hepatic ultrasonography and were deemed to have resectable tumors at the time of surgery.

\section{Patient follow-up}

The two patients groups were subjected to a close followup of 2 years. During this period they underwent clinical, radiologic (abdominal US and triphasic abdominal CT scan) and biologic (serum AFP and liver function tests) evaluations. This assessment was repeated every 3 months throughout the follow-up period.

\section{End Points}

The main end points of the study were: 1 - In-hospital mortality, morbidity and length of hospital stay. 2- The detection of early disease recurrence through the 2 year follow-up period. The impact of the type of resection (anatomic vs non-anatomic) on early disease recurrence was studied in the two groups. Other risk factors that could play a role in early tumor recurrence such as the tumor size, TNM staging, vascular invasion, pathologic grading and high AFP values were also assessed.

\section{Statistical analysis}

For continuous variables, data are presented as mean +/Standard Deviation (SD). Group comparisons were performed using univariate analysis (chi-square test or the student $t$ test as appropriate). For multivariate analysis, different factors were correlated with early tumor recurrence, and the SPSS Statistical Software (SPSS 16.0, Chicago, IL) was used for these calculations. Survival (24

Table 1: Pre-operative demographic data

\begin{tabular}{|c|c|c|c|}
\hline Variable & Anatomical & Non-Anatomical & $p$ \\
\hline Age (yr) & $62.18+/-12.09$ & $57.4+/-11.06$ & ns \\
\hline $\operatorname{Sex}(M / F)$ & $21 / 7$ & $18 / 7$ & ns \\
\hline $\mathrm{HBV}(\mathrm{y} / \mathrm{n})$ & $7 / 21$ & $5 / 20$ & ns \\
\hline $\mathrm{HCV}(\mathrm{y} / \mathrm{n})$ & $11 / 17$ & $11 / 14$ & ns \\
\hline $\mathrm{HBV}+\mathrm{HCV}(\mathrm{y} / \mathrm{n})$ & $3 / 25$ & $5 / 20$ & ns \\
\hline Cirrhosis $(y / n)$ & $8 / 20$ & $10 / 15$ & ns \\
\hline Serum albumin (gm/dl) & $3.76+/-0.34$ & $3.84+/-0.37$ & ns \\
\hline Serum bilirubin (mg/dl) & $0.86+/-0.15$ & $0.87+/-0.28$ & ns \\
\hline Child-Pugh (A/B) & $23 / 5$ & $21 / 4$ & ns \\
\hline $\operatorname{AFP}(>25 /<,=25)$ & $6 / 22$ & $9 / 16$ & ns \\
\hline
\end{tabular}


months) was calculated using the Kaplan-Meier method (Deltagraph 4.0). A $P$ value $<0.05$ was considered significant.

\section{Results}

There was no difference detected between the 2 groups in terms of clinical and demographic characteristics with respect to age, sex, viral hepatitis markers, and the presence of underlying liver cirrhosis, serum albumin, serum bilirubin, Child-Pugh classification and AFP levels (Table 1).

The tumor pathologic grades were not significantly different between the two groups with only a single poorly differentiated tumor in each group (3.5\% of the anatomic group and $4 \%$ of the non-anatomic). Two patients in the anatomic group presented with fibrolamellar HCC (FL$\mathrm{HCC}$ ) which is a rare variant of HCC that has relatively indolent tumor biology and may carry a better prognosis after complete resection [16].

Using univariate analysis methods, no difference was detected between the two groups in terms of tumor staging. Vascular invasion (T3) occurred in 9 patients in the anatomic group (32.1\%) and 7 patients in the non-anatomic group (28\%). Nodal involvement occurred in 2 patients in the anatomic group (7.1\%) and one patient in the non-anatomic group (4\%)(Table 2). Diaphragm involvement requiring resection occurred in a single patient in the anatomic group.

The overall morbidity was not statistically significant between anatomic and non-anatomic resections (21.4\% vs $28 \%$ ). This was mainly due to respiratory complications; atalectasis and occasionally respiratory distress. Other morbidities included wound infections, urinary tract infections and intra-abdominal collections which required ultrasound guided drainage. The 30-day mortality rates were not significant between the 2 groups $(p=$ 0.48 ). The three overall mortalities were caused by pulmonary embolism, liver failure and portal hypertension respectively. One occurred in the anatomic group and the other 2 were in the non-anatomic group.

Hospital stay was significantly different between the anatomic and non-anatomic groups $(6.9+/-1.5$ vs $9.6+/$ 2.7 ) with a $p$ value of 0.0004 . This difference is attributed to the surgeon preference as the majority of the non-anatomic resections were performed in TBRI-General Hospital where patients are customarily observed in hospital for longer periods of time. All operative and peri-operative outcomes are shown in (Table 2).

The majority of anatomic resections $(85.7 \%)$ were performed at Yale-New Haven Hospital while $84 \%$ of the non-anatomic resections were performed at TBRI General Hospital $(p=0.001)$ (Table 2). The tumor size \& site, the presence of underlying liver cirrhosis and the sur- geon's experience are the main factors based on which the type of resection was decided.

\section{Early tumor recurrence and possible predisposing factors}

Using the univariate analysis method, there was no difference between the 2 groups in terms of recurrence through the 24 months follow-up period. The recurrence rate was $35.7 \%$ in the anatomic group and $40 \%$ in the nonanatomic $(p=0.74)$. This suggests that the type of resection did not have an impact on early recurrence in HCC patients undergoing liver resection (Figure 1).

\section{Factors affecting early tumor recurrence}

Multivariate analysis was undertaken to correlate preoperative demographic data, tumor biologic data and operative variables with early tumor recurrence through the 24 months follow-up period in 50 patients after excluding the three early post-operative mortalities (Table 3). To clarify the predictors of early tumor recurrence after hepatectomy, 14 clinicopathologic parameters were analyzed. As a result, variables that affected early recurrence were maximal tumor diameter (Correlation Coefficient $[C C]=0.354 ; p=0.012$ ) and the tumor $\mathrm{T}$ stage which included, in addition to the tumor size, the presence of microscopic vascular invasion as a parameter of the T3 stage [17] $(\mathrm{CC}=0.366 ; p=0.009)$. The hepatectomy procedure (anatomic vs non-anatomic did not affect early recurrence either in the univariate $(p=0.74)$ or in the multivariate analysis $(\mathrm{CC}=-0.066 ; p=0.651)$.

\section{Discussion}

HCC has recently gained major clinical interest because of its increasing incidence worldwide and the potential to diagnose and treat the disease at an early stage [18-20]. Although liver transplantation has proven to be an alternative option for the surgical management of HCC in cirrhotic patients, its use is limited by the shortage of donors [21]. Hepatic resection remains the treatment of choice offering the possibility of cure, but the long-term prognosis remains unsatisfactory due to the high recurrence rate [22-24]. Early recurrence is considered one of the most important factors that impact the prognosis of HCC patients [25].

The present study attempts to determine the impact of the type of liver resection (anatomical vs. non-anatomical) on early intrahepatic tumor recurrence in a group of patients with solitary HCC. The patients were similar in preoperative clinical characteristics and tumor biology. The study showed through close follow-up over a 24 months period that the type of resection is not considered a risk factor for early tumor recurrence. On the other hand, other factors such as tumor size and microscopic vascular invasion affected early recurrence. High 
Table 2: operative variables and peri-operative outcomes

\begin{tabular}{|c|c|c|c|}
\hline Variable & Anatomical & Non-Anatomical & $P$ \\
\hline $\begin{array}{c}\text { Grade (differentiation) } \\
\text { - Well diff. }\end{array}$ & $11(39.2 \%)$ & $15(60 \%)$ & ns \\
\hline - Moderately diff. & $14(50 \%)$ & $9(36 \%)$ & ns \\
\hline - Poorly diff. & $1(3.5 \%)$ & $1(4 \%)$ & ns \\
\hline - Fibrolamellar & $2(7.1 \%)$ & 0 & ns \\
\hline TNM Stage: T1 & $3(10.7 \%)$ & $1(4 \%)$ & ns \\
\hline $\mathrm{T} 2$ & $13(46.4 \%)$ & $17(68 \%)$ & ns \\
\hline T3(vascular invasion) & $9(32.1 \%)$ & $7(28 \%)$ & $\mathrm{ns}$ \\
\hline $\mathrm{T} 4$ & $2(7.1 \%)$ & 0 & ns \\
\hline $\mathrm{N}+$ & $2(7.1 \%)$ & $1(4 \%)$ & ns \\
\hline Tumor size & $5.9+/-2.8$ & $4.1+/-1.7$ & 0.02 \\
\hline Hospital stay & $6.9+/-1.5$ & $9.6+/-2.7$ & 0.0004 \\
\hline Morbidity & $6(21.4 \%)$ & $7(28 \%)$ & $\mathrm{ns}$ \\
\hline Mortality & $1(3.5 \%)$ & $2(8 \%)$ & ns \\
\hline Recurrence & $10(35.7 \%)$ & $10(40 \%)$ & ns \\
\hline Yale/TBRI & $24 / 4$ & $4 / 21$ & 0.001 \\
\hline
\end{tabular}

Diff.: differentiated. T1: single tumor $<2 \mathrm{~cm}$ without vascular invasion, T2: single tumor $>2 \mathrm{~cm}$ without vascular invasion, T3: solitary tumor $>2 \mathrm{~cm}$ with vascular invasion, T4: tumor involving a major branch or portal or hepatic vein. $\mathrm{N}$ : nodal involvement. M: metastasis[17]

levels of AFP were not shown to have an impact on early recurrence.

Recent studies have shown that the prognosis of recurrent HCC after resection depends on the time of recurrence, supporting the hypothesis that recurrent tumors are subclinical metastases, originating from the primary tumor and missed during treatment (early recurrence), or de novo HCC arising from persistent fibrosis and hepatitis related carcinogenicity in the remnant liver (late recurrence) [26-28]. In these studies, early recurrence was associated with adverse tumor factors, especially vascular invasion, whereas late recurrence was reported to be primarily associated with the presence of cirrhosis. From these studies, only one study by Imamura et al. [27] included the type of resection as a possible risk factor for early recurrence. They concluded that non-anatomic resection is considered a risk factor for early recurrence. However, in this study non-anatomic resection was classified into tumor enucleation and limited resection. The resection margin was not identified in the resection group. In our study all patients undergoing non-anatomic resection had a $1 \mathrm{~cm}$ clear margin. A recent study by Cucchetti et al [29] compared different risk factors for early and late recurrence in cirrhotic HCC patients. They concluded that the type of resection (anatomical vs limited) is not considered a risk factor for early tumor recurrence which coincides with the results of our study. Although this study considered high AFP levels a risk factor for 


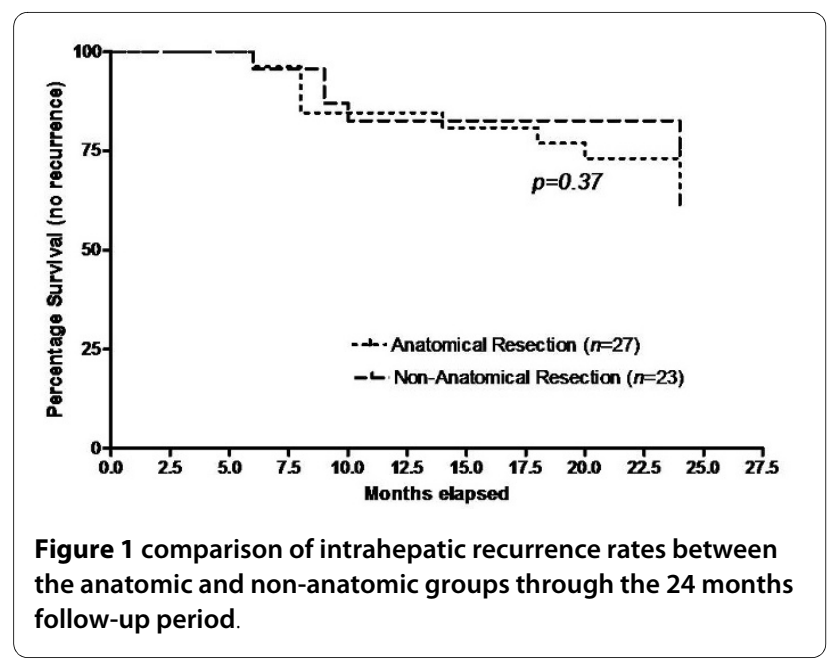

early recurrence, we attribute this to different cut-off values used for high AFP (60 ng/ml vs $25 \mathrm{ng} / \mathrm{ml})$.

While some authors have found anatomic resection to have a beneficial effect on recurrence-free survival for HCC [30], others have found that anatomic and non-anatomic resection had no significant impact on the risk of tumor recurrence $[8,31,32]$. These studies were based on overall long-term survival and therefore early and late recurrence risk factors were not taken into consideration.

While some centers pursue a policy of performing nonanatomical hepatic resections whenever possible in order to decrease the rate of postoperative hepatic failure [33], in our study only one patient died from hepatic failure during the early postoperative period. Larger studies may be required to investigate the incidence of post-operative hepatic decompensation following non-anatomic resection.

Table 3: Multivariate analysis table correlating risk factors to tumor recurrence using the SPSS Statistical Software.

\begin{tabular}{|c|c|c|c|}
\hline \multicolumn{4}{|c|}{ Recurrence } \\
\hline Risk Factors & Correlation Coefficient & $p$ & Number \\
\hline Age & 0.001 & ns & 50 \\
\hline Sex & -0.074 & ns & 50 \\
\hline HBV & 0.083 & ns & 50 \\
\hline $\mathrm{HCV}$ & 0.016 & ns & 50 \\
\hline $\mathrm{HBV}+\mathrm{HCV}$ & 0.089 & ns & 50 \\
\hline Cirrhosis & -0.017 & ns & 50 \\
\hline Total Bilirubin & -0.248 & ns & 50 \\
\hline Serum Albumin & 0.058 & ns & 50 \\
\hline Child-Pugh A & 0.176 & ns & 50 \\
\hline Abnormal AFP & 0.178 & ns & 50 \\
\hline Tumor max. diameter & 0.354 & 0.012 & 50 \\
\hline T stage & 0.366 & 0.009 & 50 \\
\hline $\mathrm{N}$ stage & 0.138 & ns & 50 \\
\hline Anatomical resection & -0.066 & ns & 50 \\
\hline
\end{tabular}


A recent study by Yoshioka et al. [34] predicted early recurrence in $\mathrm{HCC}$ after radical resection based on whole human gene expression profiling using microarray analyses. This study concluded that gene expression pattern related to early intrahepatic recurrence inherited in primary HCC can be used for the prediction of prognosis. Although our analysis focused on clinical factors affecting early tumor recurrence mainly the type of resection, further studies based on genetic analysis may provide more evidence regarding the origins of recurrent tumors.

\section{Conclusion}

Hepatic resection for HCC is a balance between the extent of resection and the preservation of hepatic function. The results of this study show that the type of resection (anatomic vs non-anatomic) is not considered a distinct risk factor for early (2 year) tumor recurrence in patients with solitary HCC and preserved liver function. Other factors such as tumor size, staging and pathologic characteristics should be considered predictors of early tumor recurrence.

\section{Competing interests}

The authors declare that they have no competing interests.

\section{Authors' contributions}

All authors have read and approved the manuscript.

\section{Author Details}

'Department of Surgery, Yale University School of Medicine, New Haven, Connecticut, USA and ${ }^{2}$ Department of Surgery, Theodor Bilharz Research Institute, Cairo, Egypt

Received: 7 March 2010 Accepted: 24 May 2010

Published: 24 May 2010

\section{References}

1. Kamangar F, Dores GM, Anderson WF: Patterns of cancer incidence, mortality, and prevalence across five continents: defining priorities to reduce cancer disparities in different geographic regions of the world. J Clin Oncol 2006, 24:2137-50.

2. Parkin DM, Bray F, Ferlay J, Pisani P: Estimating the world cancer burden: Globocan 2000. Int J Cancer 2001, 94:153-6.

3. The US National Cancer Institute. Surveillance Epidemiology and End Results (SEER) data base 2007 [http://seer.cancer.gov/].

4. Fan ST, Lo CM, Liu CL, Lam CM, Yuen WK, Yeung C, Wong J: Hepatectomy for hepatocellular carcinoma: toward zero hospital deaths. Ann Surg 1999, 229:322-30.

5. Makuuchi M, Imamura H, Sugawara Y, Takayama T: Progress in surgical treatment of hepatocellular carcinoma. Oncology 2002, 62(Suppl 1):74-81.

6. Yamanaka N, Okamoto E, Kawamura E, Kato T, Oriyama T, Fujimoto J, Furukawa K, Tanaka T, Tomoda F, Tanaka W: Dynamics of normal and injured human liver regeneration after hepatectomy as assessed on the basis of computed tomography and liver function. Hepatology 1993, 18:79-85.

7. Takano S, Oishi H, Kono S, Kawakami S, Nakamura M, Kubota N, Iwai S: Retrospective analysis of type of hepatic resection for hepatocellular carcinoma. Br J Surg 2000, 87:65-70.

8. Tanaka K, Shimada H, Matsumoto C, Matsuo K, Nagano Y, Endo I, Togo S: Anatomic versus limited nonanatomic resection for solitary hepatocellular carcinoma. Surgery 2008, 143:607-15.

9. Torzilli G, Makuuchi M, Inoue K, Takayama T, Sakamoto Y, Sugawara Y, Kubota K, Zucchi A: No-mortality liver resection for hepatocellular carcinoma in cirrhotic and noncirrhotic patients: is there a way? A prospective analysis of our approach. Arch Surg 1999, 134:984-92.

10. Kondo K, Chijiiwa K, Makino I, Kai M, Maehara N, Ohuchida J, Naganuma S: Risk factors for early death after liver resection in patients with solitary hepatocellular carcinoma. J Hepatobiliary Pancreat Surg 2005, 12:399-404.

11. Suh KS: Systematic hepatectomy for small hepatocellular carcinoma in Korea. J Hepatobiliary Pancreat Surg 2005, 12:365-70.

12. Kaibori M, Matsui $Y$, Hijikawa $T$, Uchida $Y$, Kwon AH, Kamiyama $Y$ Comparison of limited and anatomic hepatic resection for hepatocellular carcinoma with hepatitis C. Surgery 2006, 139:385-94

13. Poon RT, Fan ST, Lo CM, Ng IO, Liu CL, Lam CM, Wong J: Improving survival results after resection of hepatocellular carcinoma: a prospective study of 377 patients over 10 years. Ann Surg 2001, 234:63-70.

14. Poon RT: Differentiating early and late recurrences after resection of HCC in cirrhotic patients: implications on surveillance, prevention, and treatment strategies. Ann Surg Oncol 2009, 16:792-4.

15. Bruix JSM, AASLD PRACTICE GUIDELINE: Management of Hepatocellular Carcinoma. Hepatology 2005, 42:1208-1236.

16. Stipa F, Yoon SS, Liau KH, Fong Y, Jarnagin WR, D'Angelica M, Abou-Alfa G, Blumgart LH, DeMatteo RP: Outcome of patients with fibrolamellar hepatocellular carcinoma. Cancer 2006, 106:1331-8.

17. Beahrs OHHD, Hutter RVP, Myers MH: Manual for staging of cancer. Chicago, IL: American Joint Committee for Cancer Staging and End Results Reporting; 1988:87-89.

18. Thompson Coon J, Rogers G, Hewson P, Wright D, Anderson R, Cramp M, Jackson S, Ryder S, Price A, Stein K: Surveillance of cirrhosis for hepatocellular carcinoma: systematic review and economic analysis. Health Technol Assess 2007, 11:1-206.

19. Sherman M: Screening for hepatocellular carcinoma. Hepatol Res 2007, 37(Suppl 2):S152-65.

20. Trevisani F, De NS, Rapaccini G, Farinati F, Benvegnu L, Zoli M, Grazi GL, Del PP, Di N, Bernardi M: Semiannual and annual surveillance of cirrhotic patients for hepatocellular carcinoma: effects on cancer stage and patient survival (Italian experience). Am J Gastroenterol 2002, 97:734-44.

21. Llovet JM, Burroughs A, Bruix J: Hepatocellular carcinoma. Lancet 2003, 362:1907-17.

22. Takayama T, Makuuchi M, Hirohashi S, Sakamoto M, Yamamoto J, Shimada K, Kosuge T, Okada S, Takayasu K, Yamasaki S: Early hepatocellular carcinoma as an entity with a high rate of surgical cure. Hepatology 1998, 28:1241-6.

23. Grazi GL, Ercolani G, Pierangeli F, Del Gaudio M, Cescon M, Cavallari A, Mazziotti A: Improved results of liver resection for hepatocellular carcinoma on cirrhosis give the procedure added value. Ann Surg 2001, 234:71-8.

24. Poon RT, Fan ST, Lo CM, Liu CL, Wong J: Long-term survival and pattern of recurrence after resection of small hepatocellular carcinoma in patients with preserved liver function: implications for a strategy of salvage transplantation. Ann Surg 2002, 235:373-82.

25. Shah SA, Greig PD, Gallinger S, Cattral MS, Dixon E, Kim RD, Taylor BR, Grant DR, Vollmer CM: Factors associated with early recurrence after resection for hepatocellular carcinoma and outcomes. J Am Coll Surg 2006, 202:275-83

26. Poon RT, Fan ST, Ng IO, Lo CM, Liu CL, Wong J: Different risk factors and prognosis for early and late intrahepatic recurrence after resection of hepatocellular carcinoma. Cancer 2000, 89:500-7.

27. Imamura H, Matsuyama Y, Tanaka E, Ohkubo T, Hasegawa K, Miyagawa S, Sugawara Y, Minagawa M, Takayama T, Kawasaki S, Makuuchi M: Risk factors contributing to early and late phase intrahepatic recurrence of hepatocellular carcinoma after hepatectomy. J Hepatol 2003, 38:200-7.

28. Portolani N, Coniglio A, Ghidoni S, Giovanelli M, Benetti A, Tiberio GA, Giulini SM: Early and late recurrence after liver resection for hepatocellular carcinoma: prognostic and therapeutic implications. Ann Surg 2006, 243:229-35.

29. Cucchetti A, Piscaglia F, Caturelli E, Benvegnu L, Vivarelli M, Ercolani G, Cescon M, Ravaioli M, Grazi GL, Bolondi L, Pinna AD: Comparison of recurrence of hepatocellular carcinoma after resection in patients with cirrhosis to its occurrence in a surveilled cirrhotic population. Ann Surg Oncol 2009, 16:413-22. 
30. Regimbeau JM, Kianmanesh R, Farges O, Dondero F, Sauvanet A, Belghit $\mathrm{J}$ : Extent of liver resection influences the outcome in patients with cirrhosis and small hepatocellular carcinoma. Surgery 2002, 131:311-7.

31. Lau H, Fan ST, Ng IO, Wong J: Long term prognosis after hepatectomy for hepatocellular carcinoma: a survival analysis of 204 consecutive patients. Cancer 1998, 83:2302-11.

32. Okada S, Shimada K, Yamamoto J, Takayama T, Kosuge T, Yamasaki S, Sakamoto M, Hirohashi S: Predictive factors for postoperative recurrence of hepatocellular carcinoma. Gastroenterology 1994, 106:1618-24.

33. Ziparo V, Balducci G, Lucandri G, Mercantini P, Di Giacomo G, Fernandes E: Indications and results of resection for hepatocellular carcinoma. Eur J Surg Oncol 2002, 28:723-8.

34. Yoshioka S, Takemasa I, Nagano H, Kittaka N, Noda T, Wada H, Kobayashi S, Marubashi S, Takeda Y, Umeshita K, Dono K, Matsubara K, Monden M: Molecular prediction of early recurrence after resection of hepatocellular carcinoma. Eur J Cancer 2009, 45:881-9.

doi: 10.1186/1477-7819-8-43

Cite this article as: Eltawil et al., Differentiating the impact of anatomic and non-anatomic liver resection on early recurrence in patients with Hepatocellular Carcinoma World Journal of Surgical Oncology 2010, 8:43

Submit your next manuscript to BioMed Central and take full advantage of:

- Convenient online submission

- Thorough peer review

- No space constraints or color figure charges

- Immediate publication on acceptance

- Inclusion in PubMed, CAS, Scopus and Google Scholar

- Research which is freely available for redistribution

Submit your manuscript at www.biomedcentral.com/submit
C Biomed Central 